\title{
Characterization of Activated carbons Prepared from a Locally Available Material by Iodine Number
}

\author{
Rajeshwar Man Shrestha \\ Department of Science and Humanities, Institute of Engineering, Tribhuvan University, Nepal \\ Corresponding author: rajeshwar@ioe.edu.np
}

Received: May 11, 2017 Revised: Sep 18, $2017 \quad$ Accepted: Sep 25, 2017

\begin{abstract}
The adsorption of Iodine by the activated carbons prepared from a locally available material Lapsi Seed Stone has been studied. Various activated carbons were prepared by varying the parameters such as ratio of Lapsi Seed Stone particles to Phosphoric acid, percentage of phosphoric acid concentration, carbonization temperature and carbonization time. Determination of Iodine numbers of the activated carbons was done by the standard method. The effect of various preparation conditions on Iodine number of different activated carbons is also investigated. The optimum conditions for the preparation of activated carbon are found to be $400^{\circ} \mathrm{C}$-the carbonization temperature, 4 hours - the carbonization time, 1:1- the ratio of Lapsi Seed Stone particles and Phosphoric acid and $50 \%$ the percentage of phosphoric acid concentration
\end{abstract}

Keywords: Lapsi seed stone, activated carbon, adsorption, iodine number

\section{Introduction}

Activated carbon is carbonaceous material that has well developed pores, internal surface area and relatively high mechanical strength. It has been widely used in waste water and gas treatments as well as in catalysis. Activated carbon has many important uses including solution purification, removal of tastes and odor from domestic and industrial water supplies, vegetable and animal fats, oils, alcoholic beverages, chemicals, pharmaceuticals, removal of heavy metals and dye from water etc [11]. Most of activated carbons are prepared by a two- stage process carbonization followed by activation. Carbonization is done s to enrich the carbon content and to create an initial porosity and activation process helps in enhancing the pore structure. The activation can be carried by two different processes physical and chemical. In physical activation carbonization and activation are carried out separately. The carbonization so called pyrolysis is carried out at high temperature in inert atmosphere in order to eliminate maximum of oxygen and hydrogen elements. The second one is thermal activation at the same temperature for pyrolysis or at a higher temperature in the presence of oxidizing gases steam or carbon dioxide or both. By chemical activation it is possible to prepare activated carbon in only one step. Pyrolysis and activation are carried out simultaneously in the presence of dehydrating agents (e.g. $\mathrm{ZnCl}_{2}, \mathrm{H}_{3} \mathrm{PO}_{4}, \mathrm{H}_{2} \mathrm{SO}_{4}, \mathrm{KCl}$ etc.). In this study preparation of activated carbons from Lapsi Seed Stone by chemical activation with phosphoric acid was carried out. 
A large number of agricultural wastes have been used for the preparation of activated carbon. The waste materials such as apricot stones [6], date stones [2], guava seeds [3] black stone cherries [7], peach stones [1 \& 4], orange peel [5], Peanut shell [13] are the some examples of low-cost accessible waste materials for the production of activated carbons. Lapsi seed stone is the waste product of Lapsi fruits. Lapsi (Choerospondias axillaris) belongs to the family Anacardiaceous. It is a large, fruit bearing deciduous tree native to the hills of Nepal $(865-1900 \mathrm{~m})$. Lapsi fruit is consumed fresh, pickled or processed into a variety of sweet and sour fruit products locally called "Mada" or"Titaura". It is a rich source of vitamin C. It is also believed to aid in digestion and is often consumed after a protein rich meal. Seed stones are used as fuel in brick kilns in the factories and the trunk of the tree is used as fuel wood and timber [8\&9]. Iron impregnated activated carbon prepared from Lapsi seed stone had been investigated for the removal of arsenic from water [10].

Not much information is available regarding the preparation of activated carbon from Lapsi Seed stone using phosphoric acid as an activating agent. Activated carbon was prepared from Lapsi seed stone by chemical activation with zinc chloride for the adsorption of arsenic from water. No report is available in the literature about the preparation of activated carbon from Lapsi seed stone using phosphoric acid as an activating agent. This lack in existing literature is a motivation for the present study.

Activated carbons are usually characterized by several physical parameters such as surface area and pore volume. The surface area according to BET is then determined.The surface areas of activated carbons are usually measured using the Brunauer-Emmett-Teller (BET) method,which employs the nitrogen adsorption at different pressures at the temperature of liquid nitrogen $(77 \mathrm{~K})$. The surface area according to BET is then determined by the product of the cross-sectional area of the nitrogen molecule, of the Avogadro's number and of the specific monolayer capacity of nitrogen, which is obtained by an equation proposed by BET with further modifications. For the pore volume determination, the procedure more commonly used also uses nitrogen adsorption isotherm data. The total pore volume is estimated from the amount of nitrogen adsorbed at the highest relative pressure and the micropore volume is calculated from the nitrogen adsorption isotherms using the Dubinin-Radushkevich equation. In spite of these methods being more used and employed as a reference in the surface area and pore volume determination of porous materials, they are time consuming and require the use of expensive equipment.

Additional information about the structure of activated carbons can be obtained by the adsorption characteristics of different adsorbates, such as methylene blue and iodine. Iodine being small molecules enters into micropores while methylene blue being a big molecule is absorbed into the mesopores. Many carbons preferentially adsorb small molecules. Iodine number is the most fundamental parameter used to characterize activated carbon performance and is defined as the number of milligrams of iodine adsorbed by one gram of carbon [12]. It is a measure of activity level (higher number indicates higher degree of activation), often reported in $\mathrm{mg} / \mathrm{g}$ (typical range $500-1200 \mathrm{mg} / \mathrm{g}$ ).It is a measure of the micropore content of the activated carbon ( 0 to $20 \AA$, or up to $2 \mathrm{~nm}$ ) by adsorption of iodine from solution. The aim of this investigation was to determine Iodine number of activated carbons prepared from Lapsi Seed Stone by chemical activation with Phosphoric acid 


\section{Material and Methods}

\subsection{Preparation of Adsorbent}

The precursors used in the preparation of activated carbon are seed stones of Lapsi fruits. The fruits were collected from Fruits and Vegetable Market, Kalimati, Kathmandu. The fruits are boiled for the pulp and then seed stones are exposed and collected. The seed stones were washed well with tap water and distilled water, dried at $110^{\circ} \mathrm{C}$ and crushed to desired size $(300 \mu \mathrm{m})$ using a grinder crusher. The crushed particles were then sieved to obtain the fraction $300 \mu \mathrm{m}$. Various activated carbons were prepared by varying the parameters such as ratio of Lapsi Seed Stone particles to Phosphoric acid, percentage of phosphoric acid concentration, carbonization temperature and carbonization time. The activated carbons prepared were cooled at room temperature and were washed several times with distilled water. The materials were then dried at $110{ }^{\circ} \mathrm{C}$ for 24 hours, cooled and sieved to obtain the particles of size $106 \mu \mathrm{m}$.

\subsection{Chemicals}

All chemicals and reagents were of analytical grade (Merck and Qualigens Company). All the working solutions were prepared by diluting the stock solutions with distilled water.

\subsection{Iodine number}

The adsorption of iodine is considered a simple and quick test for evaluating the area of activated carbons associated with pores larger than $1 \mathrm{~nm}$. The iodine number, defined as the amount of iodine adsorbed per gram of activated carbon at an equilibrium concentration was measured according to the procedure established by the American Society for Testing and Materials (ASTM 2006). $100 \mathrm{mg}$ of activated carbon was added to $5 \mathrm{ml}$ of $5 \% \mathrm{HCl}$ and boiled .The solution was cooled at room temperature and added $10 \mathrm{ml}$ of $0.05 \mathrm{M}$ iodine solution. The solution was shaken for 1 min, filtered and washed with distilled water. The whole of the filtrate was titrated against $0.05 \mathrm{M}$ sodium thiosulphate solution using starch as an indicator. The iodine number was calculated by the following formula.

Iodine number $=\mathrm{C} \times$ Conversion factor

The conversion factor can be calculated as follows:

$\mathrm{C}=$ Blank reading - Volume of Hypo solution consumed after the adsorption by Activated carbon

\section{Results and Discussion}

Activated carbons were prepared from Lapsi (Choerospondias axillaris) seed stone by chemical activation with Phosphoric acid. The resultant carbons were characterized by Iodine number. Effect of various preparation parameters like ratio of Lapsi Seed Stone to Phosphoric acid, carbonization time, carbonization temperature and percentage of phosphoric acid concentration were studied. 


\subsection{Effect of Carbonization temperature and carbonization time}

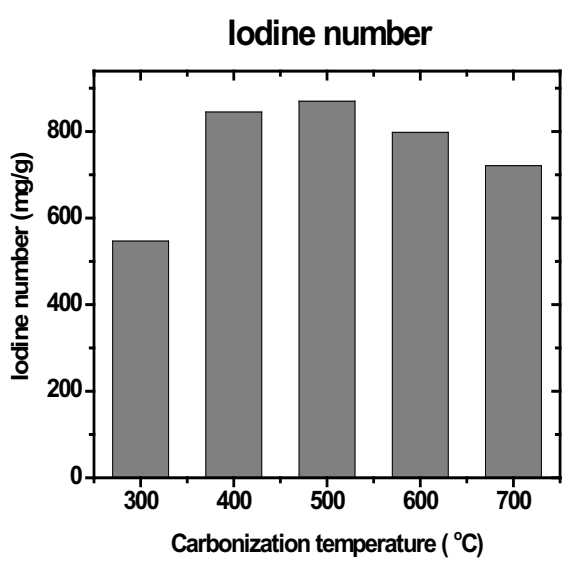

Fig. 3.1: Effect of carbonization temperature on Iodine number of activated carbons

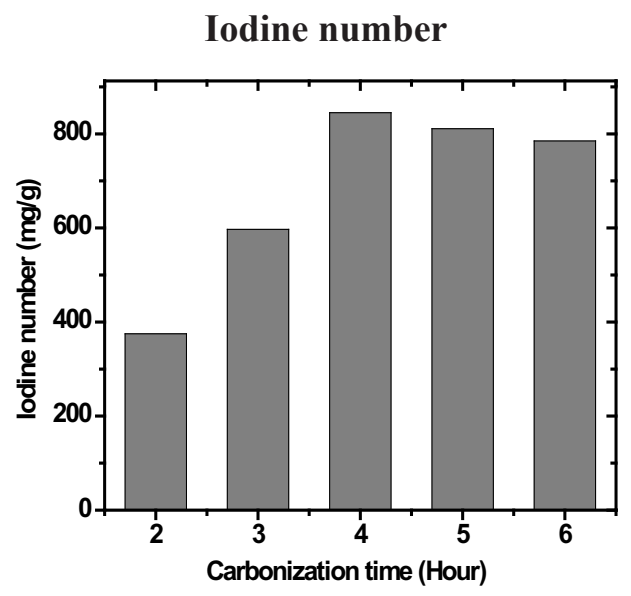

Fig. 3.2: Effect of carbonization time on Iodine number of activated carbons

The variation in iodine number of activated carbon as a function of carbonization temperature keeping other parameters such as impregnation ratio, carbonization time and concentration of phosphoric acid constant is shown in Fig. 3.1. From the Figure it is clear that iodine number increases up to $500^{\circ} \mathrm{C}$ and then decreases. Iodine is a small molecule with minimum pore diameter $10 \AA$. Iodine number gives approximate measure of the micropore content.

The results indicate that the carbonization temperature has a significant effect in the pore structure of activated carbon which ultimately determines the adsorption capacity of activated carbon. The increase in iodine number with increase in carbonization temperature may be due to the creation of more micropores and development of unsaturation in the activated carbon.

The effect of carbonization time on Iodine number of the activated carbons keeping other parameters like impregnation ratio, carbonization temperature and concentration of phosphoric acid constant is shown in Fig. 3.2. The Iodine number increases with carbonization time up to 4 hours and then after iodine number decreases

The increase in iodine number up to 4 hours may be due to escaping of tar from raw materials. After 4 hours no further development of micropores takes place but there may be widening of microspores resulting in the formation of mesopores. From this result one may conclude that 4 hours of carbonization at $400{ }^{\circ} \mathrm{C}$ is necessary to prepare the activated carbon with high iodine number. 
Iodine number

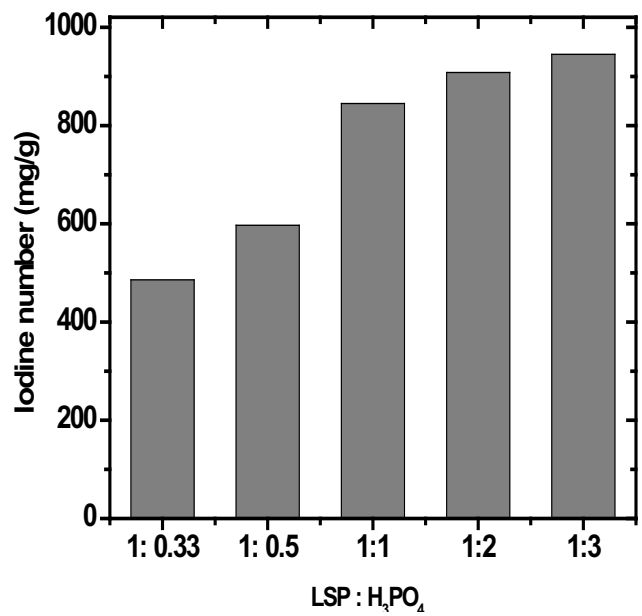

Fig. 3.3: Effect of LSP: $\mathrm{H}_{3} \mathrm{PO}_{4}$ on Iodine number of activated carbons
Iodine number

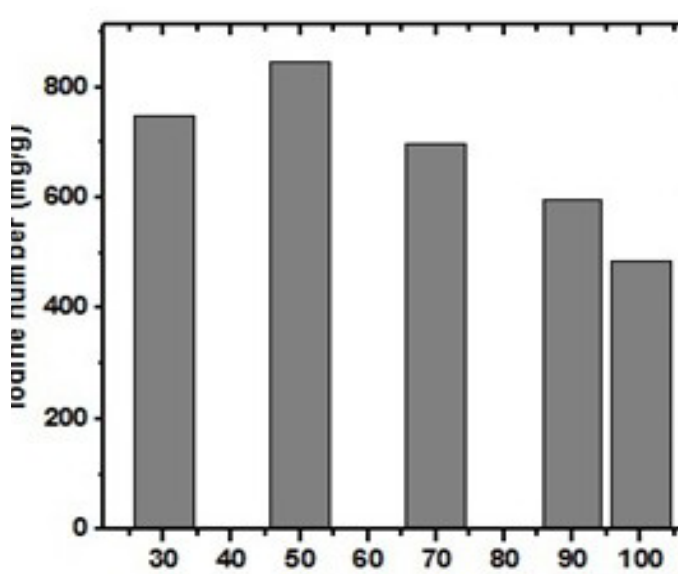

Fig. 3.4: Effect of concentration of H3PO4 on Iodine number of activated carbons

\subsection{Effect of Ratio of Lapsi Seed Stone Powder: $\mathrm{H}_{3} \mathrm{PO}_{4}$ and Concentration of Phosphoric acid}

The variation of Iodine number of the activated carbons prepared at different LSP: $\mathrm{H}_{3} \mathrm{PO}_{4}$ ratio keeping constant other parameters is shown in Fig. 3.3. The iodine number of activated carbons increases with the increase in amount of acid and after 1:1 ratio the increase is not significant. This may be due to the degeneration of pores caused by excessive dehydration with more acid

Iodine number of the activated carbons prepared by activation with different concentration of $\mathrm{H}_{3} \mathrm{PO}_{4}$ keeping other parameters constant is shown in Fig. 3.4. When the concentration of $\mathrm{H}_{3} \mathrm{PO}_{4}$ increases from $30 \%$ to $50 \% \mathrm{H}_{3} \mathrm{PO}_{4}$ iodine number increased significantly and then after from it decreases gradually. The decrease in iodine number at high concentration of phosphoric acid may be caused by degeneration of porous structures of activated carbons due to excessive dehydration.

\section{Conclusion}

The determination of Iodine number is the simple and quick method to characterize activated carbon among various activated carbons prepared. Procedure used in the determination of Iodine number is relatively cheap and simple and do not require the use of sophisticated equipment. Although this method does not substitute the proper characterization of the textural properties for activated carbons, it is valuable for laboratories in which the equipment for gas adsorption experiments is not available. The optimum conditions for the preparation of activated carbon from Lapsi Seed Stone are $400{ }^{\circ} \mathrm{C}$-the carbonization temperature, 4 Hours - the carbonization time, 1:1 - the ratio of Lapsi Seed Stone particles and Phosphoric acid and $50 \%$ - the percentage of phosphoric acid concentration.

Acknowledgement: The author wishes to express deep and sincere gratitude to Prof. Dr. Raja Ram Pradhananga, Central Department of Chemistry, Tribhuvan University, Kirtipur, Kathmandu for his valuable suggestions and moral support. 


\section{References}

[1] Amina AA, Badie SG and Nady AF (2008), Removal of methylene blue by carbons derived from peach stones by $\mathrm{H}_{3} \mathrm{PO}_{4}$ activation: Batch and column studies, Dyes and Pigments, 76: 282-289.

[2] Bouchelta C, Medjram MS, Bertrand O and Jallet JP (2008), Preparation and Characterization of activated carbon from dates stone by physical activation with steam, J. Anal. Appl. Pyrolysis, 82: 70-77.

[3] Collin GJ, Awanf B, Duduku K and Kok Onn S (2007), Sorption studies of Methylene Blue Dye in aqueous solution by Optimized Carbon Prepared from Guava Seeds (Psidium guajava L), Materials Science, 13(1) : 82-87.

[4] Dong SK (2004), Activated Carbon from Peach Stones Using Phosphoric Acid Activation at Medium Temperatures, Journal of Environmental Science and Health, 39(5): 1301-1318.

[5] Foo KY and Hameed BH (2002), Preparation, Characterization and evaluation of adsorptive properties of orange peel based activated carbon via microwave induce $\mathrm{K}_{2} \mathrm{CO}_{3}$ activation, Bioresource Technology, 104: 679- 689.

[6] Lotfi M, Djoudi M, Abdelkrim B and Lazhar B (2011), Adsorption of Pb (II) from aqueous solutions using activated carbon developed from Apricot stone, Desalination, 276: 148-153.

[7] Maria JR, Arana R and Mazzoco RR (2010), Adsorption studies of methylene blue and phenol onto black stone cherries prepared by chemical activation, Journal of Hazardous Materials, $\mathbf{1 8 0}$ : 565-661.

[8] Paudel KC and Parajuli DP (1999), Domestication and Commercialization of Lapsi tree: potential income source through agroforestry in the middle hills of Nepal. In Ministry of Science and Technology, Scientific World, Nepal 1(1) : 116-120.

[9] Paudel KC, Pieber K, Klumpp R and Laimer M (2003), Evaluation of Lapsi tree (Choerospondias axillaris, Roxb.) for fruit production in Nepal.

[10] Rajbhandari R, Shrestha LK and Pradhananga RR (2012), Nanoporous Activated Carbon Derived from Lapsi (Choerospondias axillaris) Seed Stone for the Removal of Arsenic from water, Journal of Nanoscience and Nanotechnology, 12 : 7002-7009.

[11] Sahu JN, Acharya J and Meikap B. (2010), Optimization of production conditions for activated carbons from Tamarind wood by zinc chloride using response surface methodology, Bioresource Technology, 101 : 1974-1982

[12] Shrestha RM, Yadav AP, Pokharel BP and Pradhananga RR (2012), Preparation and Characterization of Activated Carbon from Lapsi (Choerospondias axillaris) Seed Stone by Chemical Activation with Phosphoric acid, Research Journal of Chemical Sciences, 2(10) : 8086.

[13] Tau X and Xiaoqin L (2008), Peanut shell Activated Carbon: Characterization, Surface Modification and Adsorption of $\mathrm{Pb}^{+2}$ from Aqueous Solution, Chinese Journal of Chemical Engineering, 16(3) : 401- 406. 